\title{
IL-12 Family Cytokines in Inflammation and Bone Erosion of Rheumatoid Arthritis
}

\author{
Ran Wei ${ }^{1}$, Alastair J. Sloan ${ }^{2}$ and Xiao-Qing Wei $^{2}$ \\ ${ }^{1}$ Chelsea and Westminster Hospital NHS Foundation Trust, \\ ${ }^{2}$ Tissue Engineering and Reparative Dentistry, Dental School of Cardiff University, \\ UK
}

\section{Introduction}

Rheumatoid arthritis (RA) is an autoimmune disease characterised by chronic joint inflammation. The precise aetiology of this autoimmune process remains unclear. Soluble factors produced by infiltrating synovial cells play an important role in driving the inflammatory process that leads to inflammatory cell migration and proliferation in the synovial tissue. These soluble factors consist mainly of cytokines that either promote or suppress inflammation.

A number of cytokines have been identified in synovial fluid and the synovial membrane. Cytokines such as TNF $\alpha$, IL- 1 and IL- 6 stimulate T-cells and induce subsequent cartilage and bone erosion (Kang et al., 2009). Along with IL-18, these cytokines are produced by synovial macrophages and synovial fibroblasts. IL-18 causes joint inflammation and subsequent bone destruction by facilitating T-cell activation and stimulating B-cell production of autoantibodies. Deletion of the IL-18 gene in mice has been shown to result in a significant reduction in the incidence of joint inflammation and bone destruction (Wei et al., 2001).

CD4 ${ }^{+}$T-cells proliferate in inflamed synovial joints through stimulation of IL-15. Inhibition IL-15 results in a significantly lower production of TNF $\alpha$ and IL-1. As such, IL-15 blockade abolishes severe joint inflammation in collagen induced-arthritis mouse models (Ruchatz et al., 1998). In the CD4+ T-cell population, Th17 has been demonstrated as a pathogenic T-cell that produces IL-17 to induce neutrophil migration (Shibata et al., 2009). IL-17 is known to stimulate receptor-activator of nuclear factor kappa-B ligand (RANKL) production by osteoblast cells to promote osteoclastogenesis in RA bone erosion (Joosten et al., 2003). Th17 development is governed by TGF $\beta$, IL-1 $\beta$ and IL-23 (Paradowska-Gorycka et al., 2010; Santarlasci et al., 2009). Higher concentrations of IL-23 (a member of the IL-12 family cytokines) are detected in the serum and synovial fluid of patients with greater severity of RA (Melis et al., 2010). IL-23 can also be produced by osteoblast cells after stimulation with TNF $\alpha$ (unpublished data).

It is possible that remission of joint inflammation in RA patients can occur spontaneously. The fluctuation in inflammation within the joint results from auto-inhibition through the production of anti-inflammatory cytokines via regulatory T (Treg) cells (Raghavan et al., 
2009) and other regulatory mechanisms. Treg cells encompasse CD4+ T-cells and produce anti-inflammatory cytokines - such as IL-10, TGF $\beta$ and IL-35 - to suppress Th17 and other T effector cells (Sabat et al., 2010). Recent studies have identified IL-35 (a member of the IL-12 family cytokines) as a potent suppressor of Th17 cells and promoter of Treg cell expansion (Collison et al., 2007; Niedbala et al., 2007). Injection of recombinant IL-35 into mice with collagen induced-arthritis has demonstrated effective suppression of the onset of joint inflammation (Niedbala et al., 2007). The mechanism of this model is thought to be through the promotion of Treg cell activity and suppression of Th17 function (Chaturvedi et al., 2011). Despite strong evidence from in vivo animal models demonstrating the therapeutic properties of IL-35 in the treatment of joint inflammation, there continues to be a lack of evidence from in vitro human bone inflammatory models. The efficaciousness of IL-35 as an immunomodulatory therapy against RA therefore remains to be proven.

In this chapter, we will concentrate on the role of the IL-12 family cytokines - namely IL-12, IL-23, IL-27 and IL-35 in the development of rheumatoid arthritis. We will present, analyse and summarise the most recent work in our field of research. We aim to provide an up-todate and comprehensive overview of the compelling evidence and novel ideas paving way for a new generation of medical therapies against RA.

\section{2. $T$ cell activation and IL-12 family cytokines}

\section{$2.1 \mathrm{~T}$ cell activation in rheumatoid arthritis}

The main infiltrative inflammatory $\mathrm{T}$ cell in the synovial joint is the $\mathrm{CD}^{+} \mathrm{T}$ cell. Dependent on cytokine production and cell linage control cell signalling, CD4 ${ }^{+} \mathrm{T}$ cells can be divided into 4 sub-populations - Th1, Th2, Th17 and immune regulatory T (Treg) cells. These sub-types differ in function and activity. Th1, Th2 and Th17 cells act mainly as T effector cells whereas Treg cells display an immune suppressing role. T helper (Th) cell differentiation and expansion is controlled by maturated dendritic cells (DC) via three different means of signalling. The first is antigen presentation where MHC II (present on the surface of DCs) relay antigens to $T$ cell receptors (TCR) found on $T$ cells. In RA, pathological auto-antigen signalling mediated by DCs and other antigen presenting cells lead to auto-antigen induced $\mathrm{T}$ cell responses. The exact cause of this remains unclear, however, recent evidence has identified connective tissue protein and citrullinated vementin as likely mediators. Both have been shown to trigger an auto-immune $\mathrm{T}$ cell response following presentation by MHC II in RA patient (Snir et al., ; van Lierop et al., 2007). The second type of signalling is co-stimulation and is mediated via co-stimulation molecules found on DCs. An example of this is CD40 when it binds to T cell costimulation receptor (CD40L). The final means of signalling is mediated by cytokines or a group of cytokines and is the most important form of signalling generated by DCs. Cytokines produced by activated DCs bind to receptors on naïve T cells and drive T cell differentiation into Th1, Th2 or Th17. In some instances, it induces differentiation into Treg cells and suppresses over-reactive $T$ cells. In patients with RA, this complex system can result in joint inflammation that is self-limiting and accounts for the fluctuating nature of the disease. Despite vast amounts of research dedicated to investigating the precise mechanism of $\mathrm{T}$ cell development, in health and in disease, it remains a mystery. 


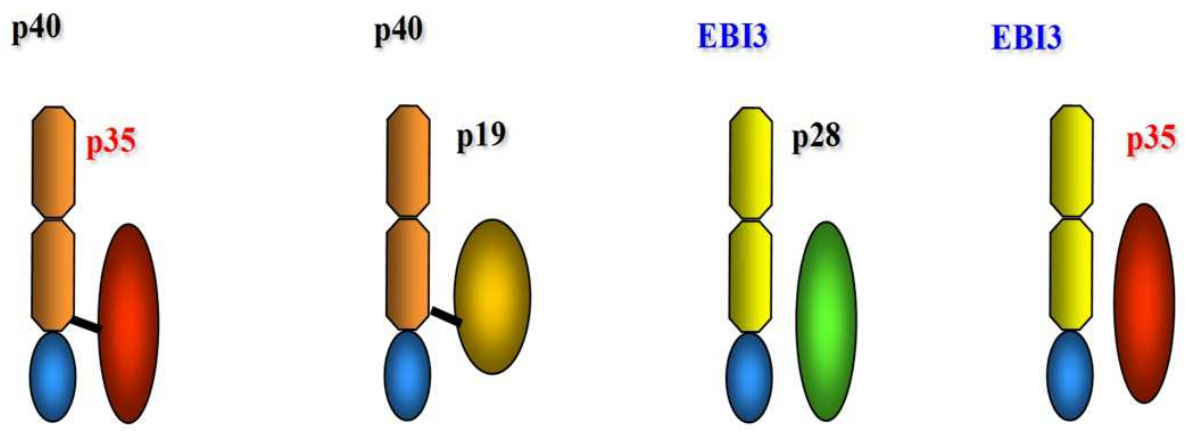

Fig. 1. Schematic representation of structure of members of the IL-12 family cytokines.

\subsection{IL-12 family cytokines in inflammation}

The cytokines involved in mediating $\mathrm{T}$ cell development belong to the IL-12 family cytokines. This family of cytokines are heterodimer secreted glycoproteins. One subunit is an IL-6 like protein and the other an IL-6 soluble receptor like protein. They are therefore also named IL-6/IL-12 family cytokines. IL-12, IL-23, IL-27 and IL-35 all belong to this IL-12 family cytokines and share certain protein subunits (Fig.1).

IL-12 consists of a p40 subunit and a p35 subunit. IL-23 consists of the same p40 subunit but couples with a p19 subunit. IL-12 was the first cytokine to be identified that had the capability of driving Th1 development (Hsieh et al., 1993; Murphy et al., 1994). IL-23 was discovered almost a decade later and was initially seen as a novel cytokine with the ability to aid Th1 development at the later stages of cell differentiation (Oppmann et al., 2000). Recent evidences suggest that IL-23 is in fact functionally very different from IL-12. Aside from its effects on Th1 cell development, IL-23 also stimulates production of IL-17 by Th17 cells (Horai et al., 2000; Zelante et al., 2007). Osteoclast formation has been shown to be upregulated by IL-23 through its effects on macrophages (Chen et al., 2008). Unlike IL-12, IL-23 plays more of a pathological role in inflammatory and autoimmune diseases.

The cytokine IL-27 is composed of a p40-related protein called EBi3 (Epstein-Barr virus induced gene 3) and a p35-related protein known as p28. EBi3 was first identified in 1996 following its expression during infection of B-lymphocyte with the Epstein Barr Virus. The gene produced was a secreted glycoprotein related to p40 (Devergne et al., 1996). p28 was discovered some years later in a research investigation of IL-6 homologous proteins using bioinformatics. The p28 protein was found only to be efficiently secreted when coupled with EBi3. Following this discovery, the heterodimeric protein of EBi3 and p28 was named as IL27 (Pflanz et al., 2002). The function of IL-27 was again, initially, thought to be similar to IL12 in driving the early stages of Th1 cell development. Further study of IL-27 has shown it to be capable of inducing IL-10 production from Treg cells and subsequently inhibiting Th17 responses (Murugaiyan et al., 2009). In inflammatory mouse disease models, such as collagen induced arthritis (CIA) mouse model, IL-27 is able to suppress inflammation (Niedbala et al., 2008).

EBi3 can be coupled with the p35 subunit of IL-12 to form a heterodimeric protein (Devergne, Birkenbach and Kieff, 1997). The function of EBi3/p35 remained a mystery until relatively recently when studies used a recombinant EBi3/p35 protein in a rheumatoid arthritis mouse model. In these experiments, joint inflammation in CIA mice was effectively 


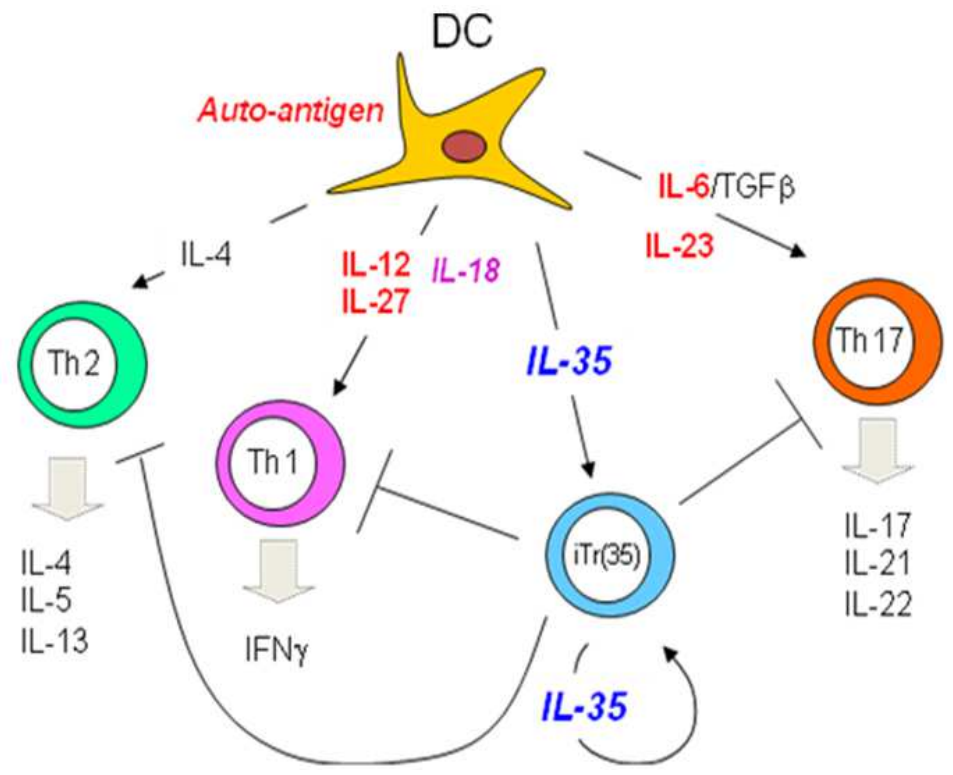

Fig. 2. Diagram showing CD4+ $\mathrm{T}$ cell differentiation resulting from production of IL-12 family cytokines produced by DCs. The presentation of auto-antigens by DCs and cytokine production result in $\mathrm{T}$ cell differentiation. The type of $\mathrm{T}$ cell response depends on the type of cytokine production in the inflammatory environment. Both DCs and $i \operatorname{Tr}(35)$, a type of Treg cell, produce IL-35 to suppress Th1, Th17 and Th2 responses.

resolved by the EBi3/p35 recombinant protein. It was suggested that the therapeutic mechanism of this recombinant protein was through induction of Treg cell development and IL-10 expression leading to suppression of Th1 and Th17 responses (Niedbala et al., 2007).

EBi3 and p35 are also highly expressed in Treg cells thus seemingly a key component of the immune regulating function of mouse Treg cells. Deficiency in either EBi3 or p35 gene in Treg cells will result in a reduced ability to suppress effector T-cell proliferation. Without EBi3 or p35, Treg cells are unable to resolve gut inflammation in mouse inflammatory bowel disease (IBD). The EBi3/p35 heterodimeric protein has since been named IL-35 (Collison et al., 2007). The functional effects of IL-35 in mouse models have been clearly demonstrated by a number of research groups. The role of this particularly cytokine in immune regulation of humans has now been confirmed (Chaturvedi et al., 2011).

\section{IL-12 family cytokines in joint inflammation of rheumatoid arthritis}

\subsection{IL-12 and IL-23 are the critical cytokines involved in joint inflammation}

Involvement of IL-12 in joint inflammation has been demonstrated in Collagen-Induced Arthritis (CIA) mouse models in early studies. Injection of recombinant IL-12 into mouse induced severe joint inflammation in CIA mouse models. Severity was markedly increased with co-administration of IL-18 and IL-12 (Leung et al., 2000). In humans, IL-12p40 can be detected in serum of RA patients in more than $40 \%$ of cases. It is also present in 
osteoarthritic patients and even healthy individuals but in significantly lower instances (Kim et al., 2000). The number of collagen type II (CII) reactive T cell in the peripheral blood mononuclear cell (PBMC) and synovial fluid monocytes (SFMCs) from RA patients was significant higher than those from osteoarthritis and health control individuals. The higher IFN $\gamma$ concentration in the culture supernatant was also associated with higher IL-12 production. This result indicated that CII reactive Th1 response is dominant in RA patients (Park et al., 2001).

Study of TNF $\alpha, T N F \alpha-R I / I I$ and IL-12 serum level in RA patients concluded that IL-12p40 levels have a stronger association with disease than TNF $\alpha$ levels (Ebrahimi et al., 2009). IL12 binds to IL-12 receptor $\beta 1$ and $\beta 2$ to trigger STAT4 phosphorylation in T cells. RA patients not only produced more IL-12p40, but are also more sensitive to IL-12 stimulation, which based on the fact of T cells from RA patients showed earlier onset and higher levels of STAT4 phosphorylation in comparison with osteoarthritis and health controls (Sun et al., 2011). To date, anti-TNF $\alpha$ therapy has been proven as the most effective therapy in treatment of rheumatoid arthritis (Radovits et al., 2009;Salliot et al., 2011). CD4 ${ }^{+} \mathrm{T}$ cells in peripheral blood mononuclear cells (PBMC) of RA patient have higher frequency of IL-12 receptor $\beta$ and lower of IL-4 receptor. The frequency of IL-12R+ T cell was remarkably reduced with both methothotrexate (MTX) therapy and anti-TNF $\alpha$ therapies (Herman et al., 2011). However another clinical study showed STAT4 phosphorylation was not induced in $\mathrm{CD}^{+} \mathrm{T}$ cells from untreated RA patients by anti-CD3 and anti-CD28, but STAT4 activation was induced in healthy individuals and anti-TNF $\alpha$ treated patients (Aerts et al., 2010). This result disagreed with previous concepts of the role of IL-12 induced Th1 responses in RA. Since STAT4 phosphorylation was not induced by IL-12, but anti-CD3 and CD28 in this experimental setting, this result may indicate anti-TNF $\alpha$ altered $\mathrm{T}$ cell response in RA patients. Since IL-12 is the only cytokine that strongly drives Th1 cell development and subsequent production of IFN $\gamma$, the role of IL-12 in RA inflammation was challenged by the studies in Collagen induced arthritis (CIA) mouse model with IFN $\gamma$ receptor gene knockout or IFNY blockade (Boissier et al., 1995; Manoury-Schwartz et al., 1997). Mice with IFN $\gamma$ gene deficiency and IFN $\gamma$ blocker did not show reduced joint inflammation but rather enhanced inflammation. These may suggest that IL-12 stimulates other cytokines to induce autoimmune joint inflammation in disease. IFN $\gamma$ production from Th1 responses is rather suppressing the joint inflammation which was seen in IL-27 suppressing joint inflammation (see section 3.2).

Comprehensive studies by using autoimmune disease mouse models with gene knockout mice have demonstrated the complexity of IL-12p40, p35 and its receptors $\beta 1$ and $\beta 2$ (Airoldi et al., 2005; Gran et al., 2002; Kikawada, Lenda and Kelley, 2003; Yoshida et al., 2009). IL-12p40 and IL-12 receptor $\beta 1$ gene knockout mice showed resistance to joint inflammation in CIA mice while IL-12p35 and IL-12RII gene knockout mice are significantly more susceptible to joint inflammation induced by collagen type II (Hoeve et al., 2006; Murphy et al., 2003). Discovery of IL-23 provided a fully explanation for the confounding phenotype in these gene knockout mice (Ooi et al., 2009). Knockout of the IL-23p19 subunit in mice showed similar levels of resistance to joint inflammation as IL-12p40 knockout (Hoeve et al., 2006). Given that IL-23 shares the same protein subunit of IL-12p40, it can be concluded that IL-23 is the key pathological cytokine in joint inflammation. To support this theory is the discovery of significantly higher levels of IL-23 in both serum and synovial fluid of RA patients (Melis et al., 2010). 


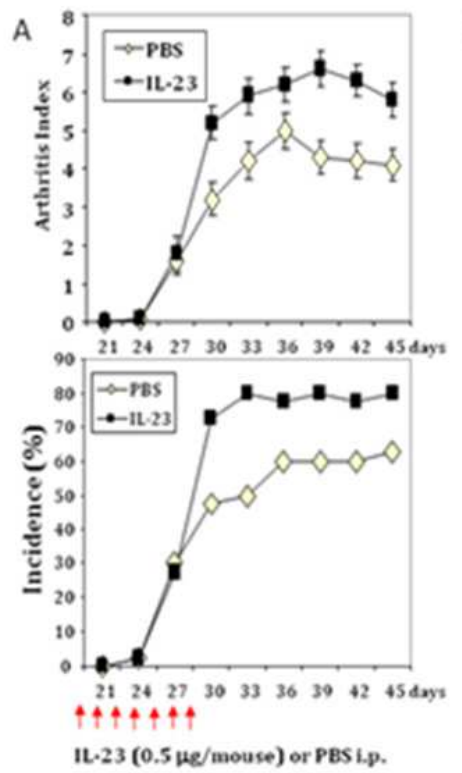

B
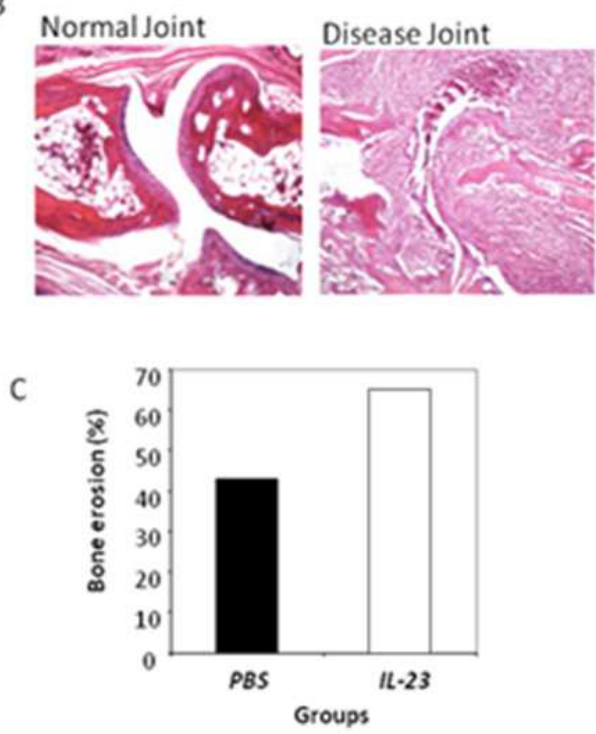

Fig. 3. IL-23 induced joint inflammation and pathology. A) Graph showing significantly higher incidence and index of severe joint inflammation in mice undergoing daily injections of $0.5 \mu \mathrm{g} /$ mouse of recombinant IL-23. B) Histology of normal and disease joints following injection of recombinant IL-23 injections. C) Incidence of bone erosion.

Results from our unpublished studies with recombinant IL-23 in CIA mice have yielded interesting findings. When recombinant IL-23 was injected into CIA mice severe joint inflammation ensued. The incidence of this was significantly higher when compared to mice injected with phosphate buffered saline (PBS). The degree of joint damage was also found to be greater in mice injected with recombinant IL-23 (Fig.3). Using ex-vivo bone slide culture models, IL-23 production has been found to increase in response to IL-1 $\beta$, TNF $\alpha$ and LPS. Astonishingly, osteoblasts also seems to contribute to IL-23 production (See section 4). IL-23 is a crucial cytokine in the Th17 response of inflammatory disorders, including RA joint inflammation. Th17 differentiates from CD4 ${ }^{+} \mathrm{T}$ cells in response to IL-1 $\beta$, IL-6 and IL-23 combinational signaling. It is distinct from Th1 and Th2 cells. Investigations into the outcome of IL-23 and Th17 targeted therapies holds potential for novel therapies against RA.

\subsection{IL-27 is dual-functional in joint inflammation}

IL-27 (consisting of an EBi3 subunit and p28 subunit) was initially identified as a Th1 driving cytokine (Pflanzet al., 2002). IL-27 binds to gp130 which is a common cytokine receptor used by many cytokines as well as growth factors [e.g. IL-6, Granulocyte Macrophage Colony Stimulation Factor (GM-CSF) and leukemia inhibition factor (LIF) etc] (Pflanz et al., 2004; Sims and Walsh, 2010). The dominant feature of IL-27 is its use of its own receptor (WSX-1) for cell signal transduction (Pflanz et al., 2004; Takeda et al., 2003). This allows it to function both as a promoter and suppressor of joint inflammation (Crabe et al., 2009; Wong et al., 2010). IL-27 promotes development of pathology by stimulating fibroblast 
like synoviocytes (FLS) for IL-6, chemokines and MMPs expression (Wonget al., 2010). However it also suppresses joint inflammation by promoting Th1 cell responses and suppressing Th17 cell responses (Pickens et al., 2011). Because IL-17 production by Th17 cells induces inflammation through recruitment of neutrophils and macrophages (Ifergan et al., 2008; Xie, Jin and $\mathrm{Yu}, 2007)$, suppressing Th17 cell responses therefore results in protection against inflammation (Niedbala et al, 2008).

The effect of IL-27 on joint inflammation differs depending on the animal model. IL-27 expression was detected in the spleen and inflamed joints of proteoglycan-induced arthritis (PGIA) mice(Cao et al., 2008). IL-27R gene knockout mice showed more resistance to PGIA than wild-type control mice. This result indicates that IL-27 plays a role in promoting joint inflammation in mice (Caoet al., 2008). However, injection of IL-27 into onset collageinduced arthritis (CIA) mice suppressed joint inflammation. This reduction in inflammation was associated with a decrease in IL-6 and IL-17 production, and an increased in IL-10 production (Niedbala et al., 2008). IL-27 local expression by injection of adenovirus carrying IL-27 gene expression resulted in reduction of joint inflammation and bone erosion in CIA mice. This effect was associated with lower serum and joint levels of IL-17 (Pickens et al., 2011). The discrepancy in the effect of IL-27 on these two different mouse models likely indicates differing disease mechanisms in these models. It is possible that the PGIA model induces joint inflammation via stimulation of synoviocytes whilst the CIA model provokes joint inflammation through initiation of T cells.

A high concentration of IL-27 is found in the synovial fluid of RA patients and has a strong positive association with levels of IFN $\gamma$ (a key cytokine produced by Th1) (Tanida et al., 2011). A negative association with IL-17 from Th17 cytokines can therefore be deduced. It would appear that IL-27 stimulates Th1 to suppress Th17 thereby prevents joint inflammation and bone/cartilage destruction (Tanida et al., 2011).

Fibroblast like synoviocyte (FLS) is a major player in generating joint inflammation in RA (Cooles and Isaacs, 2011). IL-27 receptors (gp130 and WSX-1) are expressed on FLS and render it capable of responding to IL-27 stimulation. Such stimulation leads to cell adhering molecule (ICAM-1 and VCAM-1) expression and chemokine (CXCL9 and CXCL10) production. The IL-27 response produced by FLS is synergistic with IL-1 $\beta$ and TNF $\alpha$, both being key cytokines in RA pathology (Wong et al., 2010). Given the dual-action properties of IL-27, however, its potential in therapeutic use against RA is unappealing.

\subsection{IL-35 has great potential in therapeutic treatment of RA}

Unlike IL-27, IL-35 has great pharmaceutical potential in the treatment of RA. It is a novel cytokine consisting of an EBi3 subunit and IL-12p35 subunit. These two proteins are highly expressed in the placental trophoblast and exert an immune suppressing role during pregnancy to avoid foetal rejection (Devergne et al., 2001). Transfection of cells with EBi3 and p35 expressing vectors resulted in the secretion of a heterodimeric EBi3/p35 protein (Devergne, Birkenbach and Kieff, 1997). A recombinant EBi3-p35-Fc fusion protein has been constructed. When this purified protein was injected into onset CIA mice recently, joint inflammation was significantly suppressed. This response was strongly associated with an increase in IFN $\gamma$ and IL-10 production, and a reduction in IL-17 production (Niedbala et al., 2007). Recombinant IL-35 also expands regulatory T cell (Treg) in vitro. The expanded Treg cells maintain the ability to suppress $\mathrm{T}$ effector cells for cell proliferation (Niedbala et al., 2007). IL-35 effectively inhibited IL-23 induced IL-17 production by Th17 cells in vitro. When 
compared to TNFa inhibitors, IL-35 showed greater efficacy in prevent the onset of joint inflammation in CIA model (Kochetkova et al., 2010; Niedbala et al., 2007). Both EBi3 and p35 are expressed in iTreg and contributes to its immune regulation functions (Collison et al., 2007). Treg cells from EBi3 and p35 gene knockout mice partially lost its immune suppression function in inflammatory bowel disease mice (Collison et al., 2007). Recent research found that IL-35 is able to induce a Foxp3-inducible regulatory $\mathrm{T}$ cell [iTr(35)] in vitro. This new type of $i \operatorname{Tr}(35)$ plays a role immune tolerance (Collison et al., 2010). Unlike mice, human nature Treg (nTreg) cells do not constitutively express IL-35 (Bardel et al., 2008). However, IL-35 expressing Treg cells are induced by rhinovirus activated DCs independently of Foxp3 expression (Seyerl et al., 2010). EBi3 and p35 are both expressed in human Treg cells and are the molecules required for contact-independent $\mathrm{T}$ cell suppression (Chaturvedi et al., 2011). Research into IL-35 has demonstrated its role in immune suppression. Its potential in the therapeutic treatment of RA remains to be tested. Studies so far have mainly focused on IL-35 producing T cells (Ning-Wei, 2010; Wei et al., 2011). IL-35 can be produced by a variety of cell types, such as stromal cells, macrophages and DCs. Further research using these cells may yield great insight into the actions of IL-35.

All members of the IL-12 family of cytokines can be expressed by DCs, with the type of cytokine produced dependent on the stimulus (Maroof and Kaye, 2008; van Seventer, Nagai and van Seventer, 2002). DCs are professional antigen presenting cells that drive CD4 ${ }^{+} \mathrm{T}$ cell differentiation into Th1, Th2, Th17 and Treg cells with the aid of the IL-12 family of cytokines (Collison et al., 2010; Xu et al., 2010). The interplay between expression levels and competition coupling of the IL-12 family of cytokines is complex. Alteration of this intricate system to promote or resolve joint inflammation in RA may prove to be tedious and tricky. Nonetheless, therapies that either up-regulate IL-35 production or down-regulate IL-23 should remain at the forefront of research into the treatment of RA.

\section{Inflammation induced bone and cartilage destruction in RA}

\subsection{Breaking the balance of osteoblast/osteoclast in joint inflammation 4.1.1 Osteoclastogenesis in rheumatoid arthritis}

In health, the homeostasis between osteoclasts and osteoblasts results in constant renewal of bone. Osteoclasts remove old bone matter whilst osteoblasts produce new bone. This homeostasis is maintained and controlled by a number of factors. Osteoblasts respond to changes in hormone levels, calcium concentration and interact with bone matrix protein degradation and growth factors as well as cytokines (Clarke and Khosla, 2010; Gurlek and Kumar, 2001; Izu et al., 2011). Osteoblasts produce cell membrane and soluble factors in order to direct osteoclast differentiation and maturation. The essential factors produced by osteoblasts are macrophage colony stimulatory factor (M-CSF) and receptor-activator of nuclear factor kappa-B ligand (RANKL) (Gori et al., 2000). M-CSF drives a myeloid cell linage precursor into macrophages and stimulates expression of RANK, a receptor for RANKL (Granchi et al., 2005). Further activation of macrophages by RANK mediated cell signal, on the bone surface, result in the formation of multinuclear giant cell as a result of macrophage fusion (Hofbauer et al., 2000). Fully matured osteoclasts are multinuclear tartrate resistant acitic phosphotase (TRAP) positive and express cathepsin K (Ishikawa et al., 2001). In vitro culturing of bone marrow macrophage or peripheral blood monocytes with M-CSF and soluble RANKL results in full maturation of osteoclasts with bone erosion properties (Chen et al., 2008; Granchi et al., 2005). In addition to the production of M-CSF 
and RANKL, osteoblasts also produce osteoprotegerin (OPG) that acts as a decoy receptor for RANKL. This protein suppresses osteoclast formation by blocking RANKL activity (Granchi et al., 2005). Reduction of OPG expression by osteoblasts allows up-regulation of osteoclast formation. It is the balance between RANKL and OPG expression that regulates osteoclastogenesis (Fig. 3).

In RA joints, RANKL is also produced by infiltrative T cells and FLS (Fig.4) (Dai, Nishioka and Yudoh, 2004; Okamoto and Takayanagi, 2011a; Takayanagi, 2009). RANKL production is stimulated by cytokines present in synovial fluid (Dai, Nishioka and Yudoh, 2004). RANKL is an essential factor in inflammation-induced bone erosion. Mice deficient in the RANKL gene are resistant to bone erosion in all antibody induced arthritis models (Pettit et al., 2001). Higher quantities of osteoclasts exist in the joint of RA and arthritis mouse models (Gravallese et al., 1998; Suzuki et al., 1998). Using histological staining of joint tissue, fully matured osteoclasts with multinuclear expression of TRAP and cathepsin K can be found at the pannus-bone interface and subchondral site (Gravalleseet al., 1998). Elevated soluble RANKL (sRANKL) are present in the synovial fluid of RA patients (Hein et al., 2008). FLS produces sRANKL in response to number of cytokine stimulation (Kim et al., 2007). Synovial T cells also produce sRANKL, however the specific subset of $\mathrm{T}$ cell responsible for this has not yet been identified. Cytokines produced by FLS and macrophages further stimulate sRANKL production by synovial T cells (Gracie et al., 1999). In vitro IL-18 is able to stimulate sRANKL production in isolated synovial $\mathrm{T}$ cells from a RA joint (Dai, Nishioka and Yudoh, 2004).

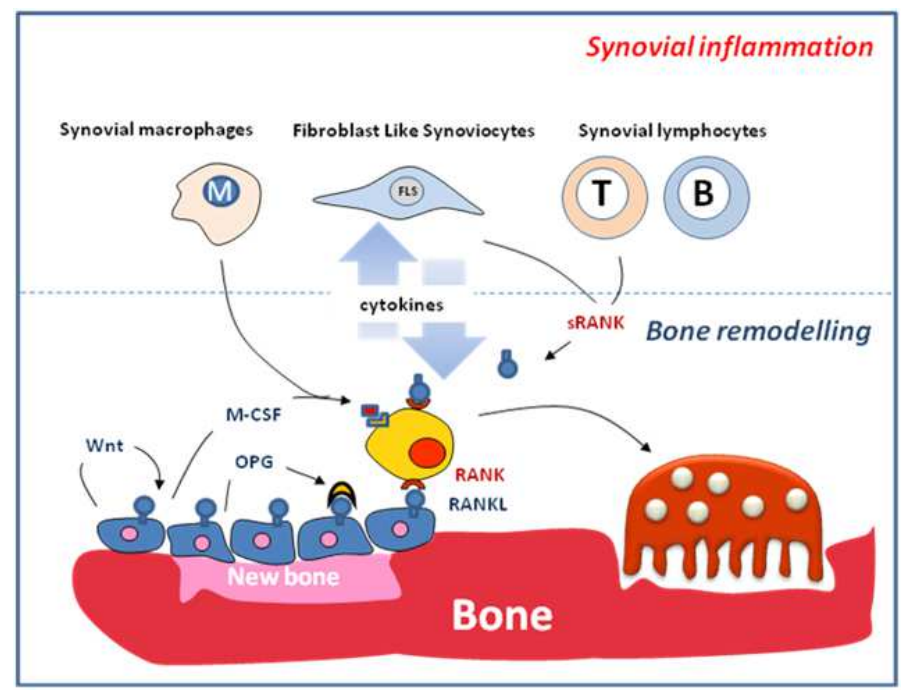

Fig. 4. Schematic diagram showing the influence of cytokines on bone remodeling in synovial joint inflammation. Synovial macrophages, fibroblast like synoviocytes, $\mathrm{T}$ and $\mathrm{B}$ cells are the main cytokine producing cells involved in RA joint inflammation. The cytokines produced by these inflammatory cells influence osteoblast and osteoclast differentiation and function. Osteoblasts produce M-CSF, RANKL and OPG in order to control TRAP+ multinuclear osteoclast formation. Osteoblast maturation and function is control by autocrine / paracrine Wnt signaling. 


\subsubsection{Osteoblast maturation in RA}

Synergistic to enhanced osteoclastogenesis in RA joints, a reduction in osteoblast activity was observed in animal models and RA patients (Cejka et al., ;Walsh et al., 2009b). Roughly $10 \%$ of RA patients on DARMs, an anti-inflammatory therapy, showed evidenced of bone regeneration (Ideguchi et al., 2006). Bone re-absorption provides strong stimulation for bone production by osteoblasts in inflamed joints (Davis et al., 2010). In RA, this response is significantly dampened in areas of inflammation when compared with healthy areas bone (Walsh and Gravallese, 2010). This indicates that cell signaling for osteoblast maturation is suppressed in inflammatory sites (Walsh et al., 2009). In healthy bone, osteoblast precursor expresses Runx2 and leads to full maturation of non-proliferative osteoblasts with expression of alkaline phosphatase, collagens and mineralization cell matrix proteins - such as osteocalcin, osteopontin and bone salioprotein (Komori, 2010).

The canonical Wingless (Wnt) signal is vital in the control of osteoblast maturation (Tamura et al., 2010). Wnt proteins are a group of secreted glycoproteins. Bone Morphogenic Proteins (BMPs) stimulate immature osteoblasts to produce Wnt proteins (Sethi and Kang, 2011). Wnt protein receptors have been identified as Frizzlrd (FZD) and low density lipoprotein receptor-related protein 5 and 6 (LRP5/6) (Takahashi et al., 2011). Osteoblasts produce endogenous inhibitors, such Dickkopf1 (DKK1), to competitively bind to LRP5 and LRP6 (Walsh et al., 2009). TNF $\alpha$ stimulates DKK1 production and therefore suppresses osteoblast development (Diarra et al., 2007). Levels of DKK1 are raised in both arthritis mouse models and human RA synovial fluid (Diarraet al., 2007). In arthritis animal models, blockade of DKK1 in vivo results in enhanced bone formation (Diarraet al., 2007). Recent clinical research into the effects of B cell depletion using Rituximab (anti-B cell antibody) on suppression of inflammation in RA patients yielded interesting results. It showed that treatment with Rituximab resulted in a reduction of bone re-absorption as well as a marked increase in bone formation (Wheater et al., 2011). These findings contribute greatly to the new and fast developing field of osteoimmunology (study of bone remodeling in inflammation). The role of the IL-12 family cytokines in regulating bone turnover is currently unclear. So far, the majority of research in this field has focused on osteoclastogenesis. In order to understand osteoblast maturation in the inflammatory environment, a greater understanding of the mechanisms behind inflammation induced joint destruction must be achieved.

\subsection{Role of IL-12 family cytokine in regulation of inflammatory bone erosion}

In RA, two key biological processes contribute to joint destruction - synovial inflammation and altered bone remodelling. Synovial inflammation results from infiltration by large numbers inflammatory cells, such as neutrophils, macrophages and $\mathrm{T}$ cells. These cells produce proteinases to degrade cell matrix proteins in both cartilage and bone. More importantly, they produce large numbers of cytokines that influence bone remodelling via effects on osteoclast and osteoblast activities. Osteoblasts and its precursors also produce cytokines in response to this stimulation (Cornish et al., 2003). The IL-12 family cytokines stimulate $\mathrm{T}$ cell responses that subsequently act on osteoclast/osteoblast precursors to promote or suppress cell differentiation (Kamiya et al., 2011). Certain members of the IL-12 family cytokines can also act on osteoclast precursors directly (Chen et al., 2008).

\subsubsection{IL-12 inhibits osteoclastogenesis in vitro and in vivo.}

The majority of research into the effect of IL-12 on osteoclastogenesis has been studied in in vitro cell culture models. Bone marrow macrophages or splenic cells have the ability to 
differentiate into fully matured $\mathrm{TRAP}^{+}$multinuclear functional osteoclasts in a culture with M-CSF and sRANKL (Chen et al., 2008). In earlier studies, IL-12 synergised with IL-18 to inhibit osteoclast formation (Yamada et al., 2002). Given that GM-CSF stimulation of bone marrow cells and splenic cells results in its differentiation into DCs, inhibition of osteoclastogenesis can be explained by GM-CSF production stimulated by IL-12 and IL-18 (Horwood et al., 2001). Bone marrow cells differentiate into macrophage 1 (M1) in response to GM-CSF and macrophage 2 (M2) in response to M-CSF (Krausgruber et al., 2011). M2 expresses higher RANK and is capable of osteoclast formation in response to RANKL. M1 and M2 are phenotypically plastic. Functional M2 cells can convert into M1 cells in a culture medium containing GM-CSF (Krausgruber et al., 2011). The reverse is also true. It can therefore be theorised that, in inflammatory joints, osteoclasts responsible for bone erosion cannot form if levels of GM-CSF and M1 cells exist. Osteoclastogenesis could occur as a result of M2 migration into inflamed joints during the inflammation resolution stage of joint disease. TNF $\alpha$ can also induce osteoclastogenesis in vivo (Kitaura et al., 2006). Injection of IL12 and TNF $\alpha$ results in reduced osteoclast formation and lower serum TRAP levels. This demonstrates that IL-12 inhibits TNF $\alpha$ stimulation of osteoclasts (Yoshimatsu et al., 2009).

\subsubsection{IL-23 promotes bone erosion via direct and indirect mechanisms}

IL-23 promotes osteoclast formation indirectly via IL-17/Th17. IL-23 is an essential cytokine in the production and maintenance of Th17 cells. IL-17 induces RANKL production in both osteoblasts and FLS (Okamoto and Takayanagi, 2011b;Yago et al., 2007). IL-17 also stimulates osteoclast precursor cells to up-regulate RANK expression and subsequently promote osteoclast formation in the presence of RANKL. Recent experiments have suggested a more direct effect of IL-23 on osteoclastogenesis. In our laboratory, we have shown IL-23 to drive osteoclast formation independent of IL-17 production in culture. IL-23 induces RANK expression in osteoclast precursor cells thereby sensitising the cells to RANKL stimulation and resulting in osteoclast development (Chen et al., 2008). Further support arose from experiments investigating osteoclastogenesis using bone marrow cells from IL-23p19 knockout mice. The direct osteoclastogenic effect of IL-23 was evidenced by greatly reduced osteoclast formation in IL-23p19 gene deficient mice (Li et al., 2010). Experiments using FLS from RA patients found that IL-23 stimulated RANKL expression with subsequent up-regulation of osteoclastogenesis and bone erosion (Li et al., 2010). IL-23 has also been suggested to stimulate GM-CSF production by $\mathrm{T}$ cells thereby inhibiting osteoclastogenesis (Quinn et al., 2008). The contradictory roles of IL-23 in bone loss secondary to inflammation are perplexing and in desperate need of further research. Interestingly, IL-23p19 knockout mice have lower bone mass (Quinn et al., 2008). This suggested that, in health, IL-23 aids the function of osteoblasts in bone formation. In our laboratory, osteoblasts have been found to induce IL-23p19 expression (unpublished data). In terms of bone remodelling in RA, these results suggest that IL-23 play multiple roles. Not only does it contribute to the functioning of osteoblasts but it also acts as a signal for communication between osteoblasts and osteoclasts.

\subsubsection{IL-27 protects joint from inflammatory bone erosion.}

IL-27 has a dual-effect in the regulation of joint inflammation. In RA, IL-27 proteins can be detected in both serum and synovial fluid (Tanida et al., 2011). In synovial fluid, CD14 ${ }^{+}$ mono-nuclear cells (MNC), not FLS, contribute to IL-27 production (Tanida et al., 2011). The 
effects of IL-27 on osteoclast formation are either direct (on osteoclast precursors) or indirect (via T cells). IL-27 acts on osteoclast precursor cells to down regulate RANK expression and suppress RANKL induced cell signalling (Kalliolias et al., 2010). IL-27 inhibits oseteoclastogensesis through blockade of M-CSF cell signalling via STAT1 dependent mechanisms (Furukawa et al., 2009). CD4 ${ }^{+} \mathrm{T}$ cells produce cell surface and soluble RANKL to promote osteoclast formation in joint inflammation (Kamiya et al., 2011). IL-27 suppresses both cell surface and soluble RANKL expressions in CD4 ${ }^{+} \mathrm{T}$ cells through suppression of the STAT3 dependent mechanism, rather than STAT1 (Kamiyaet al., 2011). These results suggest that IL-27 suppress osteoclastogenesis indirectly, via T cells.

IL-27 also acts on osteoblast cells. Osteoblasts express both receptor chains (gp130 and WSX1) for IL-27 signalling (Sims and Walsh, 2010). Cultures of human osteoblast cells in a medium containing IL-27 for 14 days showed increased production of osteoblast terminal markers, alkaline phosphatase and bone nodules (Cocco et al., 2010). Results published by a number of independent studies have shown IL-27 to protect the joint from damage in inflammatory joint disease of CIA mice (Niedbala et al., 2008).

The role of IL-35 in inflammatory bone loss is poorly understood and is yet to be studied. IL35 is capable of suppressing IL-17 production by Th17 cells (Niedbala et al., 2007; Wei et al., 2011). Both IL-27 and IL-35 appear to play salient roles in the protection against joint damage in RA. IL-35 has strong therapeutic potential in the treatment of arthritis in CIA mouse models. In order to further this potential, urgent attention on studies investigating the biological functions of IL-35 in the control of RA bone loss must be paid.

\begin{tabular}{|l|l|l|l|l|}
\hline Cytokines & CD4+ T cell & $\begin{array}{l}\text { Effects on Joint } \\
\text { inflammation }\end{array}$ & $\begin{array}{l}\text { Osteoclast } \\
\text { formation }\end{array}$ & $\begin{array}{l}\text { Osteoblast } \\
\text { maturation }\end{array}$ \\
\hline IL-12 & Th1 & Promote & Suppress & $?$ \\
\hline IL-23 & Th17 & Promote & Promote & $?$ \\
\hline IL-27 & Th1 & $\begin{array}{l}\text { Promote or } \\
\text { Suppress }\end{array}$ & Suppress & $?$ \\
\hline IL-35 & Treg & Suppress & $?$ & $?$ \\
\hline
\end{tabular}

Table 1. Summary the effects of IL-12 family cytokines in joint inflammation and bone remodelling of rheumatoid arthritis.

\section{Conclusion}

The changes in synovial joints with RA begin with inflammatory cell migration. $\mathrm{T}$ cell activation results in chronic inflammation and extra cellular matrix protein production by fibroblast-like synoviocytes. Macrophages transform into bone resorptive osteoclast cells and erode both joint cartilage and bone. In response to this, osteoblast cells mature and produce bone matrix. This leads to healing of joint destruction. IL-12 family cytokines can 
influence the responses produced by $\mathrm{T}$ cells and fibroblast like synoviocytes, and thus influence bone remodelling within inflamed joints. IL-12 family cytokines also bind to osteoblast and osteoclast precursors to either promote or suppress bone formation and erosion. Although IL-12 family cytokines have protein homology, with certain members sharing the same protein subunits, its functions in $\mathrm{T}$ cell induced inflammation and bone loss remain distinctly different (Table 1). Unlike IL-35, which suppresses the inflammatory joint response in RA, IL-12, IL-23 and IL-27 promote it. The mechanisms of action behind some of these cytokines are known whilst others are waiting to be uncovered. IL-12 drives a Th1 response whereas IL-23 promotes a Th17 response. These T cell responses lead to chronic joint inflammation. IL-12 is also a potent inducer of IFN $\gamma$ production. The immune suppression role of IFN $\gamma$ in osteoclastogenesis deems IL-12 to have a protective role against joint destruction caused by RA. On the other hand, IL-23 promotes joint inflammation and osteoclastogensis thereby causing bone erosion. IL-27 stimulates fibroblast like synoviocytes to produce a number of inflammatory factors that trigger joint inflammation. IL-27 also suppresses Th17 and therefore prevents bone loss in RA. The discovery of IL-35 in recent years has spawned a new area of research. This novel cytokine suppresses $\mathrm{T}$ cell activation and has impressive therapeutic potential against joint inflammation in RA. Its role against bone loss is unknown and requires further investigation. The role of IL-12 family cytokines in the regulation of osteoblast functions is another area in need of research. Bone erosion and joint destruction are debilitating and irreversible consequences of RA. Further exploration of IL-12 family cytokines (in particular IL-35) and their role in osteoclastogenesis needs to be undertaken without delay. Only then will the therapeutic potential of IL-35 be ready and safe to test in humans. With new therapies against RA, and potentially other autoimmune disorders, the future looks bright in this field of research.

\section{References}

Aerts, N. E., Ebo, D. G., Bridts, C. H., Stevens, W. J., and De Clerck, L. S. (2010). Clinical and experimental rheumatology 28, 208.

Airoldi, I., Di Carlo, E., Cocco, C., Sorrentino, C., Fais, F., Cilli, M., D'Antuono, T., Colombo, M. P., and Pistoia, V. (2005). Blood 106, 3846.

Bardel, E., Larousserie, F., Charlot-Rabiega, P., Coulomb-L'Hermine, A., and Devergne, O. (2008). Journal of immunology 181, 6898.

Boissier, M. C., Chiocchia, G., Bessis, N., Hajnal, J., Garotta, G., Nicoletti, F., and Fournier, C. (1995). European journal of immunology 25, 1184.

Cao, Y., Doodes, P. D., Glant, T. T., and Finnegan, A. (2008). Journal of immunology 180, 922.

Cejka, D., Hayer, S., Niederreiter, B., Sieghart, W., Fuereder, T., Zwerina, J., and Schett, G. Arthritis Rheum 62, 2294.

Chaturvedi, V., Collison, L. W., Guy, C. S., Workman, C. J., and Vignali, D. A. (2011). Journal of immunology 186, 6661.

Chen, L., Wei, X. Q., Evans, B., Jiang, W., and Aeschlimann, D. (2008). European journal of immunology 38, 2845.

Clarke, B. L., and Khosla, S. (2010). Arch Biochem Biophys 503, 118.

Cocco, C., Giuliani, N., Di Carlo, E., Ognio, E., Storti, P., Abeltino, M., Sorrentino, C., Ponzoni, M., Ribatti, D., and Airoldi, I. (2010). Clinical cancer research : an official journal of the American Association for Cancer Research 16, 4188. 
Collison, L. W., Chaturvedi, V., Henderson, A. L., Giacomin, P. R., Guy, C., Bankoti, J., Finkelstein, D., Forbes, K., Workman, C. J., Brown, S. A., Rehg, J. E., Jones, M. L., Ni, H. T., Artis, D., Turk, M. J., and Vignali, D. A. (2010). Nature immunology 11, 1093.

Collison, L. W., Workman, C. J., Kuo, T. T., Boyd, K., Wang, Y., Vignali, K. M., Cross, R., Sehy, D., Blumberg, R. S., and Vignali, D. A. (2007). Nature 450, 566.

Cooles, F. A., and Isaacs, J. D. (2011). Current opinion in rheumatology 23, 233.

Cornish, J., Gillespie, M. T., Callon, K. E., Horwood, N. J., Moseley, J. M., and Reid, I. R. (2003). Endocrinology 144, 1194.

Crabe, S., Guay-Giroux, A., Tormo, A. J., Duluc, D., Lissilaa, R., Guilhot, F., MavoungouBigouagou, U., Lefouili, F., Cognet, I., Ferlin, W., Elson, G., Jeannin, P., and Gauchat, J. F. (2009). Journal of immunology 183, 7692.

Dai, S. M., Nishioka, K., and Yudoh, K. (2004). Ann Rheum Dis 63, 1379.

Davis, J., Tucci, M., Russell, G., and Benghuzzi, H. (2010). Biomed Sci Instrum 46, 63.

Devergne, O., Birkenbach, M., and Kieff, E. (1997). Proceedings of the National Academy of Sciences of the United States of America 94, 12041.

Devergne, O., Coulomb-L'Hermine, A., Capel, F., Moussa, M., and Capron, F. (2001). The American journal of pathology 159, 1763.

Devergne, O., Hummel, M., Koeppen, H., Le Beau, M. M., Nathanson, E. C., Kieff, E., and Birkenbach, M. (1996). Journal of virology 70, 1143.

Diarra, D., Stolina, M., Polzer, K., Zwerina, J., Ominsky, M. S., Dwyer, D., Korb, A., Smolen, J., Hoffmann, M., Scheinecker, C., van der Heide, D., Landewe, R., Lacey, D., Richards, W. G., and Schett, G. (2007). Nature medicine 13, 156.

Ebrahimi, A. A., Noshad, H., Sadreddini, S., Hejazi, M. S., Mohammadzadeh Sadigh, Y., Eshraghi, Y., and Ghojazadeh, M. (2009). Iranian journal of immunology : IJI 6, 147.

Furukawa, M., Takaishi, H., Takito, J., Yoda, M., Sakai, S., Hikata, T., Hakozaki, A., Uchikawa, S., Matsumoto, M., Chiba, K., Kimura, T., Okada, Y., Matsuo, K., Yoshida, H., and Toyama, Y. (2009). Journal of immunology 183, 2397.

Gori, F., Hofbauer, L. C., Dunstan, C. R., Spelsberg, T. C., Khosla, S., and Riggs, B. L. (2000). Endocrinology 141, 4768.

Gracie, J. A., Forsey, R. J., Chan, W. L., Gilmour, A., Leung, B. P., Greer, M. R., Kennedy, K., Carter, R., Wei, X. Q., Xu, D., Field, M., Foulis, A., Liew, F. Y., and McInnes, I. B. (1999). J Clin Invest 104, 1393.

Gran, B., Zhang, G. X., Yu, S., Li, J., Chen, X. H., Ventura, E. S., Kamoun, M., and Rostami, A. (2002). Journal of immunology 169, 7104.

Granchi, D., Amato, I., Battistelli, L., Ciapetti, G., Pagani, S., Avnet, S., Baldini, N., and Giunti, A. (2005). Biomaterials 26, 2371.

Gravallese, E. M., Harada, Y., Wang, J. T., Gorn, A. H., Thornhill, T. S., and Goldring, S. R. (1998). The American journal of pathology 152, 943.

Gurlek, A., and Kumar, R. (2001). Crit Rev Eukaryot Gene Expr 11, 299.

Hein, G. E., Meister, M., Oelzner, P., and Franke, S. (2008). Rheumatology international 28, 765.

Herman, S., Zurgil, N., Machlav, S., Shinberg, A., Langevitz, P., Ehrenfeld, M., and Deutsch, M. (2011). Clinical and vaccine immunology : CVI.

Hoeve, M. A., Savage, N. D., de Boer, T., Langenberg, D. M., de Waal Malefyt, R., Ottenhoff, T. H., and Verreck, F. A. (2006). European journal of immunology 36, 661. 
Hofbauer, L. C., Khosla, S., Dunstan, C. R., Lacey, D. L., Boyle, W. J., and Riggs, B. L. (2000). J Bone Miner Res 15, 2.

Horai, R., Saijo, S., Tanioka, H., Nakae, S., Sudo, K., Okahara, A., Ikuse, T., Asano, M., and Iwakura, Y. (2000). The Journal of experimental medicine 191, 313.

Horwood, N. J., Elliott, J., Martin, T. J., and Gillespie, M. T. (2001). Journal of immunology 166, 4915.

Hsieh, C. S., Macatonia, S. E., Tripp, C. S., Wolf, S. F., O'Garra, A., and Murphy, K. M. (1993). Science 260, 547.

Ideguchi, H., Ohno, S., Hattori, H., Senuma, A., and Ishigatsubo, Y. (2006). Arthritis research $\mathcal{E}$ therapy 8, R76.

Ifergan, I., Kebir, H., Bernard, M., Wosik, K., Dodelet-Devillers, A., Cayrol, R., Arbour, N., and Prat, A. (2008). Brain : a journal of neurology 131, 785.

Ishikawa, T., Kamiyama, M., Tani-Ishii, N., Suzuki, H., Ichikawa, Y., Hamaguchi, Y., Momiyama, N., and Shimada, H. (2001). Mol Carcinog 32, 84.

Izu, Y., Sun, M., Zwolanek, D., Veit, G., Williams, V., Cha, B., Jepsen, K. J., Koch, M., and Birk, D. E. (2011). J Cell Biol 193, 1115.

Joosten, L. A., Radstake, T. R., Lubberts, E., van den Bersselaar, L. A., van Riel, P. L., van Lent, P. L., Barrera, P., and van den Berg, W. B. (2003). Arthritis and rheumatism 48, 339.

Kalliolias, G. D., Zhao, B., Triantafyllopoulou, A., Park-Min, K. H., and Ivashkiv, L. B. (2010). Arthritis and rheumatism 62, 402.

Kamiya, S., Okumura, M., Chiba, Y., Fukawa, T., Nakamura, C., Nimura, N., Mizuguchi, J., Wada, S., and Yoshimoto, T. (2011). Immunology letters.

Kang, J. W., Choi, S. C., Cho, M. C., Kim, H. J., Kim, J. H., Lim, J. S., Kim, S. H., Han, J. Y., and Yoon, D. Y. (2009). Immunology 128, e532.

Kikawada, E., Lenda, D. M., and Kelley, V. R. (2003). Journal of immunology 170, 3915.

Kim, K. W., Cho, M. L., Lee, S. H., Oh, H. J., Kang, C. M., Ju, J. H., Min, S. Y., Cho, Y. G., Park, S. H., and Kim, H. Y. (2007). Immunol Lett 110, 54.

Kim, W., Min, S., Cho, M., Youn, J., Min, J., Lee, S., Park, S., Cho, C., and Kim, H. (2000). Clin Exp Immunol 119, 175.

Kitaura, H., Tatamiya, M., Nagata, N., Fujimura, Y., Eguchi, T., Yoshida, N., and Nakayama, K. (2006). Immunol Lett 107, 22.

Kochetkova, I., Golden, S., Holderness, K., Callis, G., and Pascual, D. W. (2010). Journal of immunology 184, 7144 .

Komori, T. (2010). Cell Tissue Res 339, 189.

Krausgruber, T., Blazek, K., Smallie, T., Alzabin, S., Lockstone, H., Sahgal, N., Hussell, T., Feldmann, M., and Udalova, I. A. (2011). Nat Immunol 12, 231.

Leung, B. P., McInnes, I. B., Esfandiari, E., Wei, X. Q., and Liew, F. Y. (2000). Journal of immunology 164, 6495.

Li, X., Kim, K. W., Cho, M. L., Ju, J. H., Kang, C. M., Oh, H. J., Min, J. K., Lee, S. H., Park, S. H., and Kim, H. Y. (2010). Immunol Lett 127, 100.

Manoury-Schwartz, B., Chiocchia, G., Bessis, N., Abehsira-Amar, O., Batteux, F., Muller, S., Huang, S., Boissier, M. C., and Fournier, C. (1997). Journal of immunology 158, 5501.

Maroof, A., and Kaye, P. M. (2008). Infection and immunity 76, 239.

Melis, L., Vandooren, B., Kruithof, E., Jacques, P., De Vos, M., Mielants, H., Verbruggen, G., De Keyser, F., and Elewaut, D. (2010). Annals of the rheumatic diseases 69, 618. 
Murphy, C. A., Langrish, C. L., Chen, Y., Blumenschein, W., McClanahan, T., Kastelein, R. A., Sedgwick, J. D., and Cua, D. J. (2003). The Journal of experimental medicine 198, 1951.

Murphy, E. E., Terres, G., Macatonia, S. E., Hsieh, C. S., Mattson, J., Lanier, L., Wysocka, M., Trinchieri, G., Murphy, K., and O'Garra, A. (1994). J Exp Med 180, 223.

Murugaiyan, G., Mittal, A., Lopez-Diego, R., Maier, L. M., Anderson, D. E., and Weiner, H. L. (2009). J Immunol 183, 2435.

Niedbala, W., Cai, B., Wei, X., Patakas, A., Leung, B. P., McInnes, I. B., and Liew, F. Y. (2008). Annals of the rheumatic diseases 67, 1474.

Niedbala, W., Wei, X. Q., Cai, B., Hueber, A. J., Leung, B. P., McInnes, I. B., and Liew, F. Y. (2007). European journal of immunology 37, 3021.

Ning-Wei, Z. (2010). Revista medica de Chile 138, 758.

Okamoto, K., and Takayanagi, H. (2011a). International immunopharmacology 11, 543.

Okamoto, K., and Takayanagi, H. (2011b). Arthritis research \& therapy 13, 219.

Ooi, J. D., Phoon, R. K., Holdsworth, S. R., and Kitching, A. R. (2009). Journal of the American Society of Nephrology : JASN 20, 980.

Oppmann, B., Lesley, R., Blom, B., Timans, J. C., Xu, Y., Hunte, B., Vega, F., Yu, N., Wang, J., Singh, K., Zonin, F., Vaisberg, E., Churakova, T., Liu, M., Gorman, D., Wagner, J., Zurawski, S., Liu, Y., Abrams, J. S., Moore, K. W., Rennick, D., de Waal-Malefyt, R., Hannum, C., Bazan, J. F., and Kastelein, R. A. (2000). Immunity 13, 715.

Paradowska-Gorycka, A., Grzybowska-Kowalczyk, A., Wojtecka-Lukasik, E., and Maslinski, S. (2010). Scandinavian journal of immunology 71, 134.

Park, S. H., Min, D. J., Cho, M. L., Kim, W. U., Youn, J., Park, W., Cho, C. S., and Kim, H. Y. (2001). Arthritis and rheumatism 44, 561.

Pettit, A. R., Ji, H., von Stechow, D., Muller, R., Goldring, S. R., Choi, Y., Benoist, C., and Gravallese, E. M. (2001). Am J Pathol 159, 1689.

Pflanz, S., Hibbert, L., Mattson, J., Rosales, R., Vaisberg, E., Bazan, J. F., Phillips, J. H., McClanahan, T. K., de Waal Malefyt, R., and Kastelein, R. A. (2004). Journal of immunology 172, 2225.

Pflanz, S., Timans, J. C., Cheung, J., Rosales, R., Kanzler, H., Gilbert, J., Hibbert, L., Churakova, T., Travis, M., Vaisberg, E., Blumenschein, W. M., Mattson, J. D., Wagner, J. L., To, W., Zurawski, S., McClanahan, T. K., Gorman, D. M., Bazan, J. F., de Waal Malefyt, R., Rennick, D., and Kastelein, R. A. (2002). Immunity 16, 779.

Pickens, S. R., Chamberlain, N. D., Volin, M. V., Mandelin, A. M., 2nd, Agrawal, H., Matsui, M., Yoshimoto, T., and Shahrara, S. (2011). Arthritis and rheumatism.

Quinn, J. M., Sims, N. A., Saleh, H., Mirosa, D., Thompson, K., Bouralexis, S., Walker, E. C., Martin, T. J., and Gillespie, M. T. (2008). Journal of immunology 181, 5720.

Radovits, B. J., Fransen, J., Eijsbouts, A., van Riel, P. L., and Laan, R. F. (2009). Rheumatology $48,906$.

Raghavan, S., Cao, D., Widhe, M., Roth, K., Herrath, J., Engstrom, M., Roncador, G., Banham, A. H., Trollmo, C., Catrina, A. I., and Malmstrom, V. (2009). Annals of the rheumatic diseases 68, 1908.

Ruchatz, H., Leung, B. P., Wei, X. Q., McInnes, I. B., and Liew, F. Y. (1998). Journal of immunology 160, 5654.

Sabat, R., Grutz, G., Warszawska, K., Kirsch, S., Witte, E., Wolk, K., and Geginat, J. (2010). Cytokine $\mathcal{E}$ growth factor reviews 21, 331. 
Salliot, C., Finckh, A., Katchamart, W., Lu, Y., Sun, Y., Bombardier, C., and Keystone, E. (2011). Annals of the rheumatic diseases 70, 266.

Santarlasci, V., Maggi, L., Capone, M., Frosali, F., Querci, V., De Palma, R., Liotta, F., Cosmi, L., Maggi, E., Romagnani, S., and Annunziato, F. (2009). European journal of immunology 39, 207.

Sethi, N., and Kang, Y. (2011). Bone 48, 16.

Seyerl, M., Kirchberger, S., Majdic, O., Seipelt, J., Jindra, C., Schrauf, C., and Stockl, J. (2010). European journal of immunology 40, 321.

Shibata, S., Tada, Y., Komine, M., Hattori, N., Osame, S., Kanda, N., Watanabe, S., Saeki, H., and Tamaki, K. (2009). Journal of dermatological science 53, 34.

Sims, N. A., and Walsh, N. C. (2010). BMB reports 43, 513.

Snir, O., Rieck, M., Gebe, J. A., Yue, B. B., Rawlings, C. A., Nepom, G., Malmstrom, V., and Buckner, J. H. Arthritis Rheum.

Sun, Z. J., Zhang, Y. J., Sun, T. Z., Xiong, A., Liu, R. B., and Lu, H. S. (2011). Zhongguo gu shang = China journal of orthopaedics and traumatology 24, 295.

Suzuki, Y., Nishikaku, F., Nakatuka, M., and Koga, Y. (1998). The Journal of rheumatology 25, 1154.

Takahashi, N., Maeda, K., Ishihara, A., Uehara, S., and Kobayashi, Y. (2011). Front Biosci 16, 21.

Takayanagi, H. (2009). Nat Rev Rheumatol 5, 667.

Takeda, A., Hamano, S., Yamanaka, A., Hanada, T., Ishibashi, T., Mak, T. W., Yoshimura, A., and Yoshida, H. (2003). Journal of immunology 170, 4886.

Tamura, M., Nemoto, E., Sato, M. M., Nakashima, A., and Shimauchi, H. (2010). Front Biosci (Elite Ed) 2, 1405.

Tanida, S., Yoshitomi, H., Ishikawa, M., Kasahara, T., Murata, K., Shibuya, H., Ito, H., and Nakamura, T. (2011). Cytokine.

van Lierop, M. J., den Hoed, L., Houbiers, J., Vencovsky, J., Ruzickova, S., Krystufkova, O., van Schaardenburg, M., van den Hoogen, F., Vandooren, B., Baeten, D., De Keyser, F., Sonderstrup, G., Bos, E., and Boots, A. M. (2007). Arthritis and rheumatism 56, 2150.

van Seventer, J. M., Nagai, T., and van Seventer, G. A. (2002). Journal of neuroimmunology 133, 60.

Walsh, N. C., and Gravallese, E. M. (2010). Immunol Rev 233, 301.

Walsh, N. C., Reinwald, S., Manning, C. A., Condon, K. W., Iwata, K., Burr, D. B., and Gravallese, E. M. (2009). J Bone Miner Res 24, 1572.

Wei, X. Q., Leung, B. P., Arthur, H. M., McInnes, I. B., and Liew, F. Y. (2001). Journal of immunology 166, 517.

Wei, X. Q., Rogers, H., Lewis, M. A. O., and Williams, D. W. (2011). Clinical \& developmental immunology.

Wheater, G., Hogan, V. E., Teng, Y. K., Tekstra, J., Lafeber, F. P., Huizinga, T. W., Bijlsma, J. W., Francis, R. M., Tuck, S. P., Datta, H. K., and van Laar, J. M. (2011). Osteoporosis international : a journal established as result of cooperation between the European Foundation for Osteoporosis and the National Osteoporosis Foundation of the USA.

Wong, C. K., Chen da, P., Tam, L. S., Li, E. K., Yin, Y. B., and Lam, C. W. (2010). Arthritis research $\mathcal{E}$ therapy $12, \mathrm{R} 129$. 
Xie, Y. D., Jin, L., and Yu, Q. W. (2007). Xi bao yu fen zi mian yi xue za zhi = Chinese journal of cellular and molecular immunology 23, 536.

Xu, M., Mizoguchi, I., Morishima, N., Chiba, Y., Mizuguchi, J., and Yoshimoto, T. (2010). Clin Dev Immunol 2010.

Yago, T., Nanke, Y., Kawamoto, M., Furuya, T., Kobashigawa, T., Kamatani, N., and Kotake, S. (2007). Arthritis Res Ther 9, R96.

Yamada, N., Niwa, S., Tsujimura, T., Iwasaki, T., Sugihara, A., Futani, H., Hayashi, S., Okamura, H., Akedo, H., and Terada, N. (2002). Bone 30, 901.

Yoshida, K., Yang, G. X., Zhang, W., Tsuda, M., Tsuneyama, K., Moritoki, Y., Ansari, A. A., Okazaki, K., Lian, Z. X., Coppel, R. L., Mackay, I. R., and Gershwin, M. E. (2009). Hepatology 50, 1494.

Yoshimatsu, M., Kitaura, H., Fujimura, Y., Eguchi, T., Kohara, H., Morita, Y., and Yoshida, N. (2009). Bone 45, 1010.

Zelante, T., De Luca, A., Bonifazi, P., Montagnoli, C., Bozza, S., Moretti, S., Belladonna, M. L., Vacca, C., Conte, C., Mosci, P., Bistoni, F., Puccetti, P., Kastelein, R. A., Kopf, M., and Romani, L. (2007). Eur J Immunol 37, 2695. 


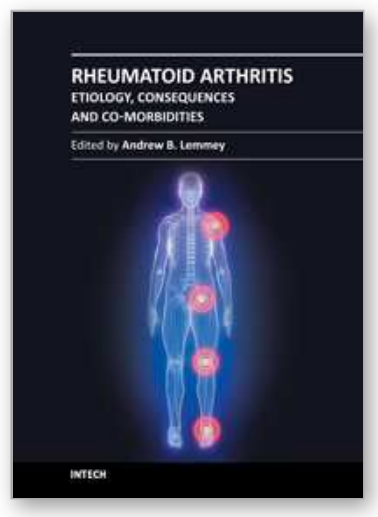

\author{
Rheumatoid Arthritis - Etiology, Consequences and Co-Morbidities \\ Edited by Dr. Andrew Lemmey
}

ISBN 978-953-307-847-2

Hard cover, 304 pages

Publisher InTech

Published online 11, January, 2012

Published in print edition January, 2012

The purpose of this book is to provide up-to-date, interesting, and thought-provoking perspectives on various aspects of research into current and potential treatments for rheumatoid arthritis (RA). This book features 16 chapters, with contributions from numerous countries (e.g. UK, USA, Japan, Sweden, Spain, Ireland, Poland, Norway), including chapters from internationally recognized leaders in rheumatology research. It is anticipated that Rheumatoid Arthritis - Etiology, Consequences and Co-Morbidities will provide both a useful reference and source of potential areas of investigation for research scientists working in the field of RA and other inflammatory arthropathies.

\title{
How to reference
}

In order to correctly reference this scholarly work, feel free to copy and paste the following:

Ran Wei, Alastair J. Sloan and Xiao-Qing Wei (2012). IL-12 Family Cytokines in Inflammation and Bone Erosion of Rheumatoid Arthritis, Rheumatoid Arthritis - Etiology, Consequences and Co-Morbidities, Dr. Andrew Lemmey (Ed.), ISBN: 978-953-307-847-2, InTech, Available from:

http://www.intechopen.com/books/rheumatoid-arthritis-etiology-consequences-and-co-morbidities/il-12-familycytokines-in-inflammation-and-bone-erosion-of-rheumatoid-arthritis

\section{INTECH}

open science | open minds

\section{InTech Europe}

University Campus STeP Ri

Slavka Krautzeka 83/A

51000 Rijeka, Croatia

Phone: +385 (51) 770447

Fax: +385 (51) 686166

www.intechopen.com

\section{InTech China}

Unit 405, Office Block, Hotel Equatorial Shanghai

No.65, Yan An Road (West), Shanghai, 200040, China

中国上海市延安西路65号上海国际贵都大饭店办公楼 405 单元

Phone: +86-21-62489820

Fax: $+86-21-62489821$ 
(C) 2012 The Author(s). Licensee IntechOpen. This is an open access article distributed under the terms of the Creative Commons Attribution 3.0 License, which permits unrestricted use, distribution, and reproduction in any medium, provided the original work is properly cited. 